Polymerization of coniferyl alcohol by Mn3+-mediated (enzymatic) oxidation : Effects of $\mathrm{H} 2 \mathrm{O} 2$ concentration, aqueous organic solvents, and $\mathrm{pH}$

\title{
Taboada-Puig, Roberto
}

2018

Taboada-Puig , R , Lu-Chau , T A , Moreira , M T, Feijoo , G , Lema , J M , Fagerstedt , K , Ohra-Aho , T , Liitia , T , Heikkinen , H , Ropponen , J \& Tamminen , T 2018 , ' Polymerization of coniferyl alcohol by Mn3+-mediated (enzymatic) oxidation : Effects of $\mathrm{H} 2 \mathrm{O} 2$ concentration, aqueous organic solvents, and pH ' , Biotechnology Progress , vol. 34 , no. 1 , pp. 81-90 . https://doi.org/10.1002/btpr.2562

http://hdl.handle.net/10138/324383

https://doi.org/10.1002/btpr.2562

unspecified

acceptedVersion

Downloaded from Helda, University of Helsinki institutional repository.

This is an electronic reprint of the original article.

This reprint may differ from the original in pagination and typographic detail.

Please cite the original version. 
Final manuscript for the publication:

'Polymerization of coniferyl alcohol by Mn3+-mediated (enzymatic) oxidation:

Effects of $\mathrm{H2O} 2$ concentration, aqueous organic solvents, and pH

Taboada-Puig, R., Lu-Chau, T. A., Moreira, M. T., Feijoo, G., Lema, J. M., Fagerstedt,

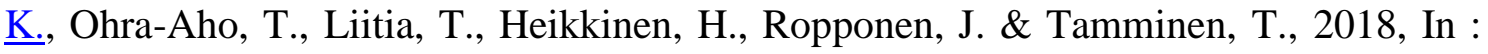
Biotechnology Progress. 34, 1, p. 81-90 10 p.

POLYMERIZATION OF CONIFERYL ALCOHOL BY A VERSATILE PEROXIDASE FROM BJERKANDERA SP: EFFECTS OF $\mathrm{H}_{2} \mathrm{O}_{2}$ CONCENTRATION, AQUEOUS ORGANIC SOLVENTS AND pH

Roberto Taboada-Puig1*, Thelmo A. Lú-Chau ${ }^{1}$, María T. Moreira ${ }^{1}$, Gumersindo Feijoo ${ }^{1}$, Juan M. Lema ${ }^{1}$, Kurt Fagerstedt ${ }^{2}$, Taina Ohra-aho ${ }^{3}$, Tiina Liitiä ${ }^{3}$, Jarmo Ropponen ${ }^{3}$, Tarja Tamminen ${ }^{3}$

${ }^{1}$ Department of Chemical Engineering, Institute of Technology, University of Santiago de Compostela, E-15782, Santiago de Compostela, Spain.

${ }^{2}$ Department of Biosciences, P.O. Box 65, FIN-00014 Helsinki University, Finland.

${ }^{3}$ VTT - Technical Research Centre of Finland Ltd, P.O. Box 1000, FI-02044 VTT, Finland.

Thelmo A. Lú-Chau (thelmo.lu@usc.es), María T. Moreira (maite.moreira@usc.es), Gumersindo Feijoo (gumersindo.feijoo@usc.es), Juan M. Lema (juan.lema@usc.es), Kurt Fagerstedt (kurt.fagerstedt@helsinki.fi), Taina Ohra-aho (taina.ohra-aho@vtt.fi), Tiina Liitiä (Tiina.Liitia@vtt.fi), Jarmo Ropponen (jarmo.ropponen@vtt.fi), Tarja Tamminen (Tarja.Tamminen@vtt.fi)

*Corresponding author:

Roberto Taboada Puig, Phd

School of Life Sciences and Biotechnology, Yachay Tech University, Hacienda San José s/n y Proyecto Yachay, San Miguel de Urcuquí - Ecuador

rtaboada@yechaytech.edu.ec

Suggested running title: Biocatalytic Polymerization of Coniferyl Alcohol 
Keywords: Polymerization; Coniferyl alcohol; Dehydrogenated Polymer; Versatile Peroxidase; Mn(III)-malonate; Bjerkandera sp. 


\section{ABSTRACT}

The objective of this study was to evaluate the ability of one versatile peroxidase and the biocatalytically generated complex $\mathrm{Mn}(\mathrm{III})$-malonate to polymerize coniferyl alcohol (CA) to obtain dehydrogenation polymers (DHPs) and to characterize the DHPs formed. Hydrogen peroxide was used as oxidant and $\mathrm{Mn}^{2+}$ as mediator. Based on the yields of the polymerized product, it was concluded that the enzymatic reaction should be performed in aqueous solution without organic solvents at $4.5 \leq \mathrm{pH} \leq 6.0$ and with 0.75 $\leq \mathrm{H}_{2} \mathrm{O}_{2}$ : $\mathrm{CA}$ ratio $\leq 1$. The results obtained from the $\mathrm{Mn}^{3+}$-malonate mediated polymerization showed that the yield was almost $100 \%$. Reaction conditions had, however, effect on the structures of the formed DHPs, as detected by size exclusion chromatography and pyrolysis-GC/MS. It can be concluded that from the structural point of view, the optimal $\mathrm{pH}$ for DHP formation using the presently studied system was 3 or 4.5. Low $\mathrm{H}_{2} \mathrm{O}_{2} / \mathrm{CA}$ ratio was beneficial to avoid oxidative side reactions. However, the high frequency of $\beta-\beta$ linkages in all cases points to dimer formation between monomeric CA rather than endwise polymerization. 


\section{SIGNIFICANCE STATEMENT}

The polymerization reactions which lead to the growth of the lignin polymer are still an aspect to elucidate due to the difficulty of their study in vivo. Dehydrogenation polymers, considered as lignin models, obtained via polymerization of monolignols by different polymerization methods differ from wood lignin structure. Therefore in the current work, three parameters affecting the catalytic cycle of the versatile peroxidase enzyme and the structure of the DHP obtained were evaluated. 


\section{INTRODUCTION}

Lignin is a heterogeneous polymer derived from phenylpropanoid monomers, mainly the hydroxycinnamyl alcohols, monolignols, coniferyl alcohol (CA) and sinapyl alcohol and minor amounts of $p$-coumaryl alcohol. These monolignols differ in their degree or aromatic methoxylation (- $\mathrm{OCH}_{3}$ group, Figure 1).

Although studies on lignin biosynthesis started many years ago, there are still several aspects to elucidate, such as lignin structure, due to the difficulty of isolating lignin without damaging its structure and also related to lignin growth since polymerization reactions cannot be studied in vivo. To overcome these drawbacks, dehydrogenation polymers (DHPs) have been considered as lignin models for research purposes (Freudenberg and Hübner, 1952). However, the structure and molecular weight of the DHPs differ from molecular weight and structures of milled wood lignin (MWL), probably because of the polymerization conditions which are different from those in the cell wall. For instance, reaction systems containing organic solvents and $\mathrm{Fe}^{3+}$ as oxidant yielded DHPs with a similar structure to that of natural lignin (Yoshida et al., 1994) but differences were found regarding the type of linkages between the monolignols. In natural lignin, the most abundant linkage is $\mathrm{\beta}-\mathrm{O}-4$ whereas the most abundant linkages in DHPs are $\beta-\beta$ or $\beta-5$ (Lewis et al., 1998). Polymerization of lignin precursors to lignin has been shown to be catalyzed by peroxidase $/ \mathrm{H}_{2} \mathrm{O}_{2}$ in plant cell walls ( $\underline{\text { Harkin and Obst, }}$ 1973). It was demonstrated that a radical carrier, which works similarly to $\mathrm{Fe}^{3+}$, may function in the dehydrogenative polymerization catalyzed by peroxidase/ $\mathrm{H}_{2} \mathrm{O}_{2}$.

In that way, Önnerud et al. (2002) demonstrated the ability of $\mathrm{Mn}^{3+}$, generated by manganese peroxidase ( $\mathrm{MnP}$ ) enzyme, to initiate the polymerization of monolignols into lignin-type structures without any direct contact between the enzyme and the monolignol. Moreover, due to their limited access to the enzyme, authors also performed DHP synthesis with chemically generated $\mathrm{Mn}(\mathrm{III})$ in an acidic water:dioxane mixture. Although the yield of the enzyme-generated DHPs was 5\%, approximately, the structure of the DHP obtained was very similar to an isolated lignin such as MWL. In the current work, a similar lignin modifying enzyme, versatile peroxidase (VP), which produces two ions of $\mathrm{Mn}^{3+}$ during its $\mathrm{Mn}$-oxidizing catalytic cycle ( $\mathrm{MnP}$ activity) was used 
to polymerize CA and to obtain $\beta-0-4$ rich DHPs, which more closely approximates the structure of native lignin.

The Mn-oxidizing catalytic cycle of VP includes successive conversions in which the enzyme is oxidized by $\mathrm{H}_{2} \mathrm{O}_{2}$ to a two-electron oxidized intermediate, VPI. VPI removes one electron from the substrate and passes the electron to a one-electron-oxidized species, VPII. At this stage of the catalytic cycle, organic substances and $\mathrm{Mn}^{2+}$ can serve as electron donors. VPII removes another electron from the substrate, and subsequently, the enzyme returns to its native form. The oxidation of $\mathrm{Mn}^{2+}$ generates $\mathrm{Mn}^{3+}$, which is a strong oxidative species $(1.54 \mathrm{~V})$ and acts as a mediator in the degradation of organic compounds at locations remote from the enzyme active site (Cui and Dolphin, 1990). That is, target substrates are oxidized by $\mathrm{Mn}^{3+}$ and not directly by the enzyme.

Several parameters can affect the enzymatic activity and the amount and structure of the polymer obtained, such as the $\mathrm{H}_{2} \mathrm{O}_{2} / \mathrm{CA}$ ratio $\left(\mathrm{mol} / \mathrm{mol}, R_{C A}\right)$, reaction medium $\mathrm{pH}$ and the presence of organic solvents miscible in water.

Concerning the $R_{C A}$, as shown in Figure 1, during the polymerization of CA two moles of the oxidizing agent $\left(\mathrm{Mn}^{3+}\right)$ per mol of substrate (CA) are needed from a stoichiometric point of view; therefore one mol of $\mathrm{H}_{2} \mathrm{O}_{2}$ per mol of $\mathrm{CA}$ is necessary, equation [A].

$$
\mathrm{H}_{2} \mathrm{O}_{2}+2 \mathrm{Mn}^{2+} \stackrel{\mathrm{MnP}}{\longrightarrow} 2 \mathrm{Mn}^{3+}+2 \mathrm{OH}^{-}
$$

Regarding the $\mathrm{pH}$ of the reaction medium, it affects both the stability of the enzyme and the structure of the DHPs. Concerning the enzyme, the highest oxidizing capability has been shown to be at pH 4.5 (Taboada-Puig et al., 2011b); however, acidic $\mathrm{pH}$ is not very favorable for stability, corresponding the highest stability of this enzyme at pH 6 (Taboada-Puig et al., 2011a). Concerning the structure of the DHP, during polymerization a quinone methide intermediate is formed (Figure 2); this intermediate is stabilized by the addition of hydroxyl groups from various nucleophiles depending on the $\mathrm{pH}$ value. In neutral and slightly acidic solutions (pH 6 and 7), the only dimeric product formed is the benzyl aryl ether (B). At pH 3, the addition of water becomes the predominant reaction to form guaiacylglycerol- $\beta$-guaiacyl ether $(A)$, which is the desired product. At near neutral or slightly basic $\mathrm{pHs}(7.5-8)$, the main dimeric reaction product 
is still the benzyl aryl ether (B), whereas the main dimeric product at $\mathrm{pH}$ higher than 9 is the retro-aldol product (C) (Sipilä and Brunow, 1991).

Finally, the use of organic solvents miscible in water as reaction media improves the solubility of the aromatic compounds and polymerization products which are poorly soluble in water. Therefore, organic solvents are expected to enhance the molecular weight of the DHPs.

The first objective of this study was to analyze the ability of VP to polymerize coniferyl alcohol, selected as a model compound, to produce dehydrogenation polymers (DHPs). To do so, the effects of $\mathrm{H}_{2} \mathrm{O}_{2}$ concentration $\left(R_{C A}\right), \mathrm{pH}$ and water-miscible organic solvents on the polymerization yield $\left(Y_{p}\right)$ of coniferyl alcohol by VP were assessed.

In addition, the ability of the continuously biocatalytically generated complex $\mathrm{Mn}^{3+}$ malonate (Taboada-Puig et al., 2015) to polymerize the coniferyl alcohol into DHP was also evaluated.

\section{RESULTS AND DISCUSSION}

\subsection{ENZYMATIC POLYMERIZATION}

Three parameters were assessed for their effect on the polymerization of coniferyl alcohol: $\mathrm{H}_{2} \mathrm{O}_{2} / \mathrm{CA}$ ratio $\left(\mathrm{mol} / \mathrm{mol}, R_{C A}\right), \mathrm{pH}$ and use of water-miscible organic solvents.

\section{$\underline{\mathrm{H}}_{2} \underline{\mathrm{O}}_{2} / \mathrm{CA}$ ratio}

The effect of $\mathrm{H}_{2} \mathrm{O}_{2} /$ CA ratio was evaluated at five different levels: 0.5, 0.75, 1 (the stoichiometric ratio), 1.5 and 2 (Figure 3a). The highest polymerization yield value was obtained at $R_{C A}=1(98.3 \pm 3.5 \%)$, but there is no statistically significant difference with the polymerization yield obtained at $R_{C A}=0.75(91.8 \pm 9.6 \%)$. This could be explained because a ratio of 0.5 was enough during the initial polymerization step but during the propagation step, a ratio of 1 was necessary (Figure 1). Therefore, a ratio between 0.75 and 1 is likely to be enough to fulfill complete polymerization. Moreover, no statistical differences were observed with the polymerization yields obtained after enzymatic treatments with $R_{C A}$ values of $1.50(76.3 \pm 11.0)$ and $2.0(77.8 \pm 3.9)$

However, statistical differences were found ( $p=0.03171$ ) when $R_{C A}$ was reduced to 0.5 (58.3 $\pm 25.2 \%)$. This drop was probably due to the fact that the amount of oxidizing agent is half of the theoretically required value. On the other hand, the residual MnP activity 
of VP was $50.6 \pm 7.1 \%$ and $48.5 \pm 12.3 \%$ at ratios of 1.5 and 2.0 , respectively; i.e. at high hydrogen peroxide concentrations. Hydrogen peroxide concentration is, probably, the most important variable in the catalytic cycle of VP. It is necessary to initiate the catalytic cycle, but an excessively high concentration can inactivate the enzyme through the formation of the inactive form VPIII (Martínez, 2002). Therefore, in terms of polymerization yields all condition for $R_{c A}$, except for $0.5 \mathrm{~mol} / \mathrm{mol}$, are good enough, nevertheless, in terms of enzymatic deactivation the best results were obtained at $R_{C A}=$ 0.75 or $1 \mathrm{~mol} / \mathrm{mol}$.

\section{$\mathrm{pH}$ of the reaction medium}

The effect of $\mathrm{pH}$ was evaluated at four different levels: 3, 4.5 (highest oxidizing capacity of VP), 6 (highest stability of VP) and 7.5. The highest polymerization yield $(99.3 \pm 1.2 \%)$ was attained at $\mathrm{pH} 6$; nevertheless, no statistical differences were observed in comparison with the polymerization yield at $\mathrm{pH} 4.5(91.7 \pm 10.4 \%), 3(84.17 \pm 9.25 \%)$ or $7.5(77.50 \pm 19.25 \%)$. At those $\mathrm{pH}$ values, the observed enzymatic deactivation was negligible $(\mathrm{pH} 4.5)$ or $29.0 \pm 3.4 \%(\mathrm{pH} 6)$, whereas the highest enzymatic deactivation was observed at $\mathrm{pH} 3$ and 7.5 (Figure $3 \mathrm{~b}$ ).

\section{Presence of organic solvents miscible in water}

The effect of three water miscible organic solvents was evaluated in the polymerization of coniferyl alcohol. The ability of the enzyme to produce DHPs dropped drastically due to the presence of the organic solvents, which is concomitantly reflected in the precipitation yield values, $57.5 \%, 25.5 \%$ and $21.5 \%$ for acetone, acetonitrile, and 1 ,4dioxane, respectively. After $24 \mathrm{~h}$ of reaction, the residual enzymatic activity was negligible leading to very low polymerization yield. Due to the fact that the presence of organic solvents led to low polymerization yields and high enzymatic deactivation, samples from these experiments were not further analyzed.

\section{2. $\mathrm{Mn}^{3+}$-MALONATE MEDIATED POLYMERIZATION}

The enzymatic reactor ([1], Figure 4) was operated at the following conditions: 250, 25 and $25 \mu \mathrm{M} / \mathrm{min} \mathrm{Na}$-malonate, $\mathrm{MnSO}_{4}$ and $\mathrm{H}_{2} \mathrm{O}_{2}$ feeding rates, respectively, $200 \mathrm{U} / \mathrm{L} \mathrm{MnP}$ activity and HRT of $70 \mathrm{~min}$, to produce the highest level of $\mathrm{Mn}^{3+}$-malonate (TaboadaPuig et al., 2015). In these conditions, the concentration of the complex $\mathrm{Mn}^{3+}$-malonate 
obtained after the ultrafiltration membrane was $871 \mu \mathrm{M}$. The complex was fed to the polymerization reactor ([2], Figure 4) at $292 \mu \mathrm{L} / \mathrm{min}$, i.e. the feeding rate of the complex to the polymerization reactor was $0.2543 \mu \mathrm{mol} / \mathrm{min}$, whereas the coniferyl alcohol was fed at $0.46125 \mu \mathrm{mol} / \mathrm{min}$. Despite that the molar ratio $\mathrm{Mn}^{3+}: \mathrm{CA}$ was 0.55 while it should be 2 , the results obtained from the $\mathrm{Mn}^{3+}$-malonate mediated polymerization showed that the yield was almost complete $(96.50 \%)$.

The first conclusion of this part of the study is that the polymerization of the coniferyl alcohol can be performed by both systems: enzyme VP-catalyzed polymerization and $\mathrm{Mn}^{3+}$-malonate mediated polymerization. In terms of polymerization yield, the direct VP enzyme reaction should be performed in aqueous solution with no organic solvent at $\mathrm{pH}$ between 4.5 and 6.0 and with an $R_{C A}$ ratio between 0.75 and 1.

\subsection{CHARACTERIZATION OF THE DHPS}

Reaction conditions were expected to have considerable effects on the structures of the formed DHPs. Thus, the second aim of this work was to identify the conditions that would be optimal regarding the similarity of the polymer to lignin structure rather than only optimizing the yield of the product. Detailed structural analyses of the formed DHPs were therefore performed.

\subsubsection{SIZE EXCLUSION CHROMATOGRAPHY}

The non-uniformity of the chain lengths of lignin precludes the characterization of a specific molecular weight. Thus, it is necessary to characterize lignin in terms of average molecular weight. The distribution obtained from GPC/SEC is typically a molecular weight distribution describing how much material there is present of the various molecular weights.

Size exclusion chromatography (SEC) analysis showed that $R_{C A}$ had a clear effect on the degree of polymerization (Table 1). Higher weight average molecular weight (Mw) DHPs were produced under $R_{C A}$ ratios of 1.0-1.5 $\mathrm{H}_{2} \mathrm{O}_{2} / \mathrm{CA}(\mathrm{mol} / \mathrm{mol})$ and also highest polydispersity (PDI) values were obtained in the $R_{C A}$ ratios of $1.0-1.5 \mathrm{H}_{2} \mathrm{O}_{2} / \mathrm{CA}$ (mol/mol) which indicates that very heterogeneous distributions were obtained. 
The comparison of these results with those from natural lignin is not straightforward since the values of average molecular weight $(\mathrm{Mn}), \mathrm{Mw}$ and $\mathrm{Pd}$ parameters strongly depend on the pre-treatments conditions applied to isolate the lignin (Tolbert et al., 2014). For instance, the comparison of the molecular weight (Mw) of MWL ( $10^{4} \mathrm{~g} \mathrm{~mol}^{-}$ $\left.{ }^{1}\right)$ against lignin extracted from steam exploded $\left(\sim 10^{4} \mathrm{~g} \mathrm{~mol}^{-1}\right)$ and autohydrolyzed $\left(\sim 10^{3}\right.$ $\mathrm{g} \mathrm{mol}^{-1}$ ) aspen revealed that autohydrolysis yielded a 10 -fold reduction in molecular weight at the severity studied (Li and Gellerstedt, 2008). However, it can be concluded that the DHPs produced in all $R_{C A}$ conditions were in the same magnitude order than lignin (Tolbert et al., 2014).

On the other hand, significantly lower $M w$ values were measured for the samples prepared at $\mathrm{pH}$ values 3,6 and 7.5 (Table 1); although the samples were not visibly cloudy before the measurements, probably they were not fully soluble and therefore unfortunately not representative. The same effect occurred with the samples from the $\mathrm{Mn}^{3+}$-malonate experiments were not completely soluble in the eluent, and thus the high molar mass material may be excluded from the measurement.

\subsubsection{PYROLYSIS-GAS CHROMATOGRAPHY/MASS SPECTROMETRY}

The analytical method of py-GC/MS is widely used for the characterization of lignin structure. As the degradation is thermal, the solubility of the samples is not required. The ether bonds $\left(\mathrm{R}-\mathrm{O}-\mathrm{R}^{\prime}\right)$ in the lignin are the primary target functional groups to decompose during the pyrolysis (Mu et al., 2013); therefore, during the pyrolysis, lignin is degraded to rather simple phenols as a result of cleavage of ether ( $\left.R-O-R^{\prime}\right)$. Great advantage of this technique is that most of phenols retain their substitution patterns from the lignin polymer. It is possible to identify components from $p$-hydroxyphenyl, guaiacyl and syringyl units. Guaiacyl type components are mainly formed from softwood lignin, whereas hardwood lignin degrades to guaiacyl and syringyl type units. Also some $p$-hydroxyphenyl type components, which are typical structures for the non-wood materials, are formed from both wood types. In this study, pyrolysis was used to characterize DHPs polymerized from coniferyl alcohol. Thus, it is expected that pyrolysis of these DHPs will have similar type of degradation products than softwood lignin (Sjöström, 1993). 
After integration, pyrolysis yield is calculated as the sum of peak areas of DHPs derived products normalized to the weight of the sample. The yield of pyrolysis products is related to the abundance of non-condensed structures, as only $\mathrm{C}-\mathrm{O}$ bonds are expected to be extensively cleaved in pyrolysis (Kuroda et al., 1994). In order to evaluate structural changes on various DHPs, peak areas of $p$-hydroxyphenyl and guaiacyl derivatives were normalized to $100 \%$. Two parallel py-GC/MS measurements were done for each DHP sample and the averages of peak areas were calculated. The average variation between total peak areas of two parallel measurements was as high as $30 \%$. Placement and staying of lignin sample on the filament, which is heated, is challenging and may explain the high variation between peak intensities. Profiles of lignin derived products between two parallel measurements were however alike.

\section{a. EFFECT OF $\mathrm{H}_{2} \underline{\mathrm{O}}_{2} / \mathrm{CA}$ RATIO}

The DHPs produced by enzymatic polymerization of coniferyl alcohol with various $\mathrm{H}_{2} \mathrm{O}_{2} / \mathrm{CA}$ ratios were studied. Theoretical $\mathrm{H}_{2} \mathrm{O}_{2} / \mathrm{CA}$ ratio optimum is 1.0 ; therefore sample with $R_{C A}=1.0$ was used as a reference. The yield of pyrolysis products with $\mathrm{H}_{2} \mathrm{O}_{2} / \mathrm{CA}$ ratios of $0.5,0.75,1.0,1.5$ and 2.0 was found to be same, since no statistical differences were found (Figure 5a).

Concerning the structure, only minor changes were observed in the different $\mathrm{H}_{2} \mathrm{O}_{2} / C A$ ratios. At low $\mathrm{H}_{2} \mathrm{O}_{2}$ concentration more guaiacyl type structures with no oxygen in side chain were formed from DHP in comparison to reference DHP. Profiles were similar when $\mathrm{H}_{2} \mathrm{O}_{2} / C A$ ratios were 0.75 and 1.0. The result indicates that $\mathrm{H}_{2} \mathrm{O}_{2} / C A$ ratio of 0.75 is close to the theoretical optimum value, whereas when an excess of $\mathrm{H}_{2} \mathrm{O}_{2}$ was used, the proportion of trans-coniferyl alcohol and coniferaldehyde was changed in comparison to the reference DHP (Figure 6a).

\section{b. EFFECT OF $\mathrm{pH}$}

The DHPs produced by enzymatic CA polymerization at different $\mathrm{pH}$ values were studied. Theoretical $\mathrm{pH}$ value optimum is 4.5; therefore it was used as a reference. After having analyzed the results applying an analysis of variance, it is concluded that no statistical 
differences were found for the pyrolysis yield (Figure 5b). However, the change of $\mathrm{pH}$ affected the proportions of degradation products formed from DHPs (Figure 6b).

The proportion of guaiacyl structures, mainly 4-methylguaiacol and trans-isoeugenol with no oxygen in the side chain, was increased at increasing $\mathrm{pH}$ values, whereas the proportion of coniferyl aldehyde was decreased. Based on the model compound studies, 4-methylguaiacol is the main degradation product of $\beta-5$ structure (Kuroda and Nakagawa-izumi, 2006). Thus, the increase of 4-methylguaiacol may indicate higher proportions of $\beta-5$ structure in DHP at higher $\mathrm{pH}$. The decrease of guaiacyl structures containing oxygen in the side chain, which are expected to be originated as a result of the cleavage of $\beta-0-4$ ether bonds in lignin, means lower proportion of $\beta-0-4$ bonds in DHP.

\section{c. $\mathrm{Mn}^{3+}$-MALONATE MEDIATED POLYMERIZATION}

The yield of pyrolysis products was higher $(p=0.046)$ for the DHPs polymerized using $\mathrm{Mn}^{3+}$-malonate in comparison to the polymerization attained with VP (Figure 5c). DHPs structures prepared by using $\mathrm{Mn}^{3+}$-malonate were nearly identical to the ones obtained by enzymatic treatment at $\mathrm{pH}$ 4.5. The main difference is the proportion of guaiacol, vinylguaiacol and trans-coniferyl alcohol, which is higher in the DHPs produced by enzymatic treatment (Figure 6c).

Due to the difficulties to observe the variations in such a large data set, multivariate analysis using principle component analysis (PCA), which is designed for visualization of similarities and differences between samples, was used to evaluate pyrolysis data obtained for the DHPs samples. PCA shows the underlying structure of data and presents it in two or three-dimensional figures so that major trends and dominant patterns can be overviewed. Two principal components that describe the variance of the data were calculated. Both guaiacyl and p-hydroxyphenyl lignin units normalized separately to $100 \%$ for each sample were subjected to PC analysis (same data as illustrated in Figure 6). The score plot (Figure 7a) shows how the samples are related to each other based on the pyrolysis data, whereas the loading plot (Figure $7 \mathbf{b}$ ) shows which degradation products are important for the classification of the samples evaluated in the score plot. 
Based on the pyrolysis results, production of DHPs at various $\mathrm{H}_{2} \mathrm{O}_{2} / C A$ ratios $\left(R_{C A}\right)$ did not much change the polymer structure. The proportion of $p$-hydroxyphenyls and benzenediols, as well as vanillin and homovanillin, is higher in $\mathrm{H}_{2} \mathrm{O}_{2} / C A$ series, except for conditions $R_{C A}=0.5$, than that for the other DHPs. DHPs prepared at high $\mathrm{pH}$ produce, during the pyrolysis, high proportion of guaiacyl structures with no oxygen in the side chain whereas at low pH high proportion of guaiacyl structures with oxygen in the side chain is produced. DHPs polymerized by $\mathrm{Mn}^{3+}$-malonate mediated polymerization processes have similar structure as DHP polymerized by enzymatic process at low $\mathrm{pH}$.

\section{CONCLUSIONS}

VP-catalyzed polymerization of coniferyl alcohol (CA) into dehydrogenation polymer DHP was successful under various reaction conditions. For optimal polymerization yield, the reaction should be performed in aqueous solution with no organic solvent at $\mathrm{pH}$ between 4.5 and 6.0 and with a $\mathrm{H}_{2} \mathrm{O}_{2} / \mathrm{CA}$ ratio between 0.75 and 1 .

Structural analyses of the DHPs revealed that high $\mathrm{H}_{2} \mathrm{O}_{2}$ addition and especially high $\mathrm{pH}$ during the reaction induced polymerization products that differ from native lignin. From the structural point of view, the optimal conditions for DHP formation using the presently studied system would be $\mathrm{pH} 3$ or 4.5 , using $\mathrm{H}_{2} \mathrm{O}_{2} / \mathrm{CA}$ ratio of 0.5 . These conditions are similar that would be expected in the lignifying cell walls of e.g. tree xylem.

\section{MATERIALS AND METHODS}

\subsection{PRODUCTION OF VERSATILE PEROXIDASE}

Versatile peroxidase (VP) was obtained from submerged cultures of the anamorph R1 of Bjerkandera sp (Taboada-Puig et al., 2011b). The fungus was grown in a $42 \mathrm{~L}$ fermenter, BIOSTAT $^{\oplus} \mathrm{C}+$ from Sartorius Stedim Biotech (Melsungen, Germany) containing $30 \mathrm{~L}$ of medium with the following composition: $10 \mathrm{~g} \mathrm{~L}^{-1}$ glucose (Panreac, Castellar del Vallès, Spain), $2 \mathrm{~g} \mathrm{~L}^{-1}$ peptone (Sigma-Aldrich, St. Louis, MO, USA), $500 \mu \mathrm{M} \mathrm{MnSO} 4$ (Panreac, Castellar del Vallès, Spain) and $100 \mathrm{~mL}$ BIII mineral salts (Tien and Kirk, 1988) in $20 \mathrm{mM}$ sodium acetate buffer (Panreac, Castellar del Vallès, Spain). The extracellular culture broth was collected at the point of highest VP activity (typically after 4-6 d) and filtered 
through Whatman No. 1 paper filters (Maidstone, United Kingdom). The filtered culture broth containing the enzyme was concentrated by ultrafiltration (Filtron Minisette System, Pall Corporation, Hauppauge, NY, USA; 10 kDa cut-off) to final VP activities of around $10 \mathrm{U} \mathrm{mL} \mathrm{L}^{-1}$ and finally stored at $-21 \stackrel{\circ}{\circ}$ until used. The strain did not produce laccase under the applied culture conditions. Four different peroxidases were purified: R1B1, R1B2, R1B3, R1B4, differing in the degree of glycosylation from cultures of the anamorph R1 of Bjerkandera sp. using the same medium. The R1B4 isoenzyme was the major fraction ( $81 \%)$ and it was identified to be a versatile peroxidase.

\subsection{DETERMINATION OF MANGANESE-DEPENDENT ACTIVITY OF VP}

Manganese-dependent activity of VP was measured spectrophotometrically (Shimadzu UV-Visible Spectrophotometer UV-1603, Japan) by monitoring the oxidation of 2,6dimethoxyphenol (DMP; Fluka, Buchs, Switzerland; 97\%) at $468 \mathrm{~nm}$ and $30 \stackrel{\circ}{\circ}\left(\varepsilon_{468}=\right.$ $49.6 \mathrm{mM}^{-1} \mathrm{~cm}^{-1}$, referred to the oxidation product, coerulignone). The reaction mixture contained 50 mM sodium malonate ( $\mathrm{pH}$ 4.5; Sigma-Aldrich; $\geq 98 \%$ ), 1 mM DMP, 1 mM $\mathrm{MnSO}_{4}$ (Merck, Darmstadt, Germany; p.a.) and $50 \mu \mathrm{L}$ of sample in a total volume of 1 $\mathrm{mL}$. The reaction was started by adding $0.4 \mathrm{mM} \mathrm{H} \mathrm{O}_{2}$ (Sigma-Aldrich; $30 \% \mathrm{w} / \mathrm{v}$ ). One enzyme unit was defined as the amount of enzyme producing $1 \mu \mathrm{mol}$ of coerulignone per minute (Mester et al., 1995). Assays containing buffer instead of sample served as blanks.

VP is able to oxidize DMP directly with a lower catalytic efficiency as compared to $\mathrm{Mn}^{2+}$ (Taboada-Puig et al., 2011b). Within the scope of this study, the assay was considered to be sufficiently specific for $\mathrm{Mn}^{2+}$. Residual activity was calculated as the ratio between the enzymatic activity at the end of each experiment and the initial enzymatic activity.

\subsection{SYNTHESIS OF CONIFERYL ALCOHOL}

Coniferyl alcohol was synthesized according to literature (Quideau and Ralph, 1992). Ferulic acid was esterified with ethanol under acidic conditions into ethyl ferulate, which was purified and reduced to coniferyl alcohol by DIBAL-H.

\subsection{POLYMERIZATION OF CONIFERYL ALCOHOL}

\subsubsection{ENZYMATIC POLYMERIZATION}


The enzymatic polymerization of coniferyl alcohol (CA) was performed as follows: $20 \mathrm{mg}$ of CA was dissolved in a $20 \%$ mixture of 1,4 -dioxane and sodium malonate buffer at $\mathrm{pHs}$ of $3,4.5,6$ and 7.5 in a total volume of $5 \mathrm{~mL}$ and it was placed in a $5 \mathrm{~mL}$-syringe. A second $5 \mathrm{~mL}$-syringe contained a mixture of $\mathrm{H}_{2} \mathrm{O}_{2}(11.1-44.4 \mathrm{mM})$ and $\mathrm{MnSO}_{4}(22.2-88.8 \mathrm{mM})$. Both solutions were added dropwise for $4 \mathrm{~h}$ to a $25 \mathrm{~mL}$ Erlenmeyer flask containing 10 $\mathrm{mL}$ of aqueous or water-miscible organic solvent solution with VP (200 U/L as MnP activity). The reaction mixture was then stirred overnight at room temperature. After 24 $h$, the organic solvent was removed by evaporation under reduced pressure, $\mathrm{pH}$ adjusted to 2.5 and the precipitated polymer was finally recovered by centrifugation. The solid was washed with a large excess of acidic distilled water $(\mathrm{pH} 2.5)$ to remove unreacted coniferyl alcohol and low molecular weight oligomers. Thereafter, it was collected by centrifugation and vacuum-dried. The polymerization yield $\left(Y_{p}\right)$ was determined as the ratio between the weight of the collected polymer and the initial amount of CA.

\subsection{2. $\mathrm{Mn}^{3+}$-MALONATE MEDIATED POLYMERIZATION}

The polymerization of CA by $\mathrm{Mn}^{3+}$-malonate was performed as shown in Figure 4: $20 \mathrm{mg}$ of CA was dissolved in a $20 \%$ mixture of 1,4-dioxane and water in a total volume of 30 $\mathrm{mL}$. It was placed in a $30 \mathrm{~mL}$-syringe and added dropwise for $4 \mathrm{~h}$ to the polymerization reactor with a CA feeding rate of $0.46125 \mu \mathrm{mol} / \mathrm{min}$. $\mathrm{Mn}^{3+}$-malonate was continuously added dropwise from a stock solution of $875 \mu \mathrm{M}(70 \mathrm{~mL})$ at a feeding rate of 0.292 $\mathrm{mL} / \mathrm{min}$, which means $0.2543 \mu \mathrm{mol} / \mathrm{min}$. The complex had been previously produced in the "two-stage" system, which consisted of a stirred tank reactor [1] operated in continuous mode coupled to a 10 kDa cut-off ultrafiltration membrane [3] (Prep/ScaleTFF Millipore). Cofactors were added to the reactor from two stock solutions: $\mathrm{H}_{2} \mathrm{O}_{2}$ and a mixture of $\mathrm{Mn}^{2+}$ and $\mathrm{Na}$ - malonate at $\mathrm{pH}$ 4.5.

\subsection{STRUCTURAL CHARACTERIZATION OF DHPS}

Pyrolysis GC/MS was performed with a filament pulse pyrolyzer (Pyrola2000, Pyrol AB Sweden) which was connected to a GC/MS instrument (Varian 3800 GC/2000 MS). About $100 \mu \mathrm{g}$ of the sample was pyrolyzed at $580^{\circ} \mathrm{C}$ for $2 \mathrm{~s}$. Pyrolysis products were 
separated using a capillary column (J\&W, DB-1701, $30 \mathrm{~m} \times 0.25 \mathrm{~mm}$, film $1 \mu \mathrm{m}$ ) using a carrier gas flow of $0.9 \mathrm{~mL} / \mathrm{min}$. Identification and quantification were done with an ion trap mass spectrometer (El $70 \mathrm{eV}$ ). A more detailed description of the method is elsewhere (Ohra-aho et al., 2005). Degradation products formed were identified using data from the literature (Faix et al., 1991a, Faix et al., 1991b, Ralph and Hatfield, 1991). The molar mass measurements were performed by Waters HPLC in $0.1 \mathrm{M} \mathrm{NaOH}$ eluent using PSS's MCX 1000 and $100000 \AA$ columns with UV detection at $280 \mathrm{~nm}$. The average molar masses $(\mathrm{Mw}, \mathrm{Mn})$ and the molar mass distributions were calculated relative to Na-polystyrene standards (Na-PSS, 3 420-148 $500 \mathrm{~g} / \mathrm{mol}$ ) using Waters Empower 2 software. For the analysis, about $4 \mathrm{mg}$ of sample was dissolved overnight in $4 \mathrm{ml}$ analytical $\mathrm{NaOH}(0.1 \mathrm{M})$ and filtered with $0.45 \mu \mathrm{m}$ PTFE membrane syringe filters (VWR).

\subsection{STATISTICAL ANALYSIS}

Statistical analysis was conducted with the software R (version 2.8.1) to determine the optimal $\mathrm{R}_{\mathrm{CA}}(\mathrm{mol} / \mathrm{mol})$ and $\mathrm{pH}$ and peroxide addition strategy as a function of polymerization yield and pyrolysis yield after the enzymatic treatment

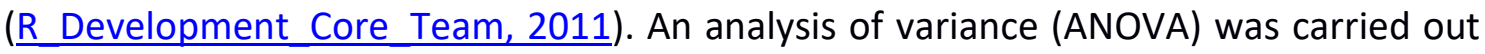
to determine if the values obtained at the different levels of the measured parameters were significantly different. Then, if the ANOVA confirmed the difference between the mean values, a post hoc analysis (Tukey's HSD) was used to determine between which values that difference was significant, considering a level of significance of $p=0.05$. 


\section{ACKNOWLEDGMENTS}

This study was supported by the Spanish project CTQ2010-20258 and the European project EUI2008-03703. The authors from the USC belong to the Galician Competitive Research Group GRC 2013-032 (program co-funded by FEDER) and to the strategic group CRETUS (AGRUP2015/02). The experiments were carried out at VTT Technical Research Centre of Finland Ltd. Tekes is acknowledged for financial support to VTT via project "Products from Lignocellulose" in the ERA-IB project. R. Taboada-Puig would like to express his gratitude to the Spanish Ministry of Science and Innovation for his financial support (BES-2008-006977). T. Lú-Chau thanks the Galician Government (I. Barreto program) for providing financial support. 


\section{SHORT LEGENDS}

CA: coniferyl alcohol

DHP: dehydrogenated polymer

GPC: gel permeation chromatography

MnP: manganese peroxidase

Mn: number average molecular weight

Mw: weight average molecular weight

MWL: milled wood lignin

p: level of significance

PDI: polydispersity

Py-GC/MS: pyrolysis gas chromatography/mass spectrometry

$\mathrm{R}_{\mathrm{CA}}: \mathrm{H}_{2} \mathrm{O}_{2} / \mathrm{CA}$ ratio (mol/mol)

SEC: size exclusion chromatography

VP: versatile peroxidase

$\mathrm{Y}_{\mathrm{p}}$ : polymerization yield 


\section{REFERENCES}

Cui, F. and Dolphin, D. (1990) The Role of Manganese in Model Systems Related to Lignin Biodegradation. In Holzforschung - International Journal of the Biology, Chemistry, Physics and Technology of Wood, pp. 279.

Faix, O., Fortmann, I., Bremer, J. and Meier, D. (1991a) Thermal degradation products of wood. Holz als Roh- und Werkstoff, 49, 299-304.

Faix, O., Fortmann, I., Bremer, J. and Meier, D. (1991b) Thermal degradation products of wood. Holz als Roh- und Werkstoff, 49, 213-219.

Freudenberg, K. and Hübner, H.H. (1952) Oxyzimtalkohole und ihre Dehydrierungspolymerisate. Chemische Berichte, 85, 1181-1191.

Harkin, J.M. and Obst, J.R. (1973) Lignification in Trees: Indication of Exclusive Peroxidase Participation. Science, 180, 296-298.

Kuroda, K.-i. and Nakagawa-izumi, A. (2006) Analytical pyrolysis of lignin: Products stemming from $\beta-5$ substructures. Organic Geochemistry, 37, 665-673.

Kuroda, K., Yamaguchi, A. and Sakai, K. (1994) Analysis of sugi wood and its lignin preparations by pyrolysis-gas-chromatography. Mokuzai Gakkaishi, 40, 987-995.

Lewis, N.G., Davin, L.B. and Sarkanen, S. (1998) Lignin and Lignan Biosynthesis: Distinctions and Reconciliations. In Lignin and Lignan Biosynthesis: American Chemical Society, pp. 1-27.

Li, J. and Gellerstedt, G. (2008) Improved lignin properties and reactivity by modifications in the autohydrolysis process of aspen wood. Industrial Crops and Products, 27, 175-181.

Martínez, A.T. (2002) Molecular biology and structure-function of lignin- degrading heme peroxidases. Enzyme Microb Tech, 30, 425-444.

Mester, T., de Jong, E. and Field, J.A. (1995) Manganese regulation of veratryl alcohol in white rot fungi and its indirect effect on lignin peroxidase. Appl Environ Microb, 61, 1881-1887.

Ohra-aho, T., Tenkanen, M. and Tamminen, T. (2005) Direct analysis of lignin and ligninlike components from softwood kraft pulp by Py-GC/MS techniques. Journal of Analytical and Applied Pyrolysis, 74, 123-128. 
Önnerud, H., Zhang, L., Gellerstedt, G. and Henriksson, G. (2002) Polymerization of Monolignols by Redox Shuttle-Mediated Enzymatic Oxidation: A New Model in Lignin Biosynthesis I. The Plant Cell, 14, 1953-1962.

Quideau, S. and Ralph, J. (1992) Facile large-scale synthesis of coniferyl, sinapyl, and pcoumaryl alcohol. Journal of Agricultural and Food Chemistry, 40, 1108-1110.

Ralph, J. and Hatfield, R.D. (1991) Pyrolysis-GC-MS characterization of forage materials. Journal of Agricultural and Food Chemistry, 39, 1426-1437.

Sipilä, J. and Brunow, G. (1991) On the Mechanism of Formation of Non-Cyclic Benzyl Ethers During Lignin Biosynthesis. Part 2. The Effect of $\mathrm{pH}$ on the Reaction between a B-O-4-Type Quinone Methide and Vanillyl Alcohol in WaterDioxane Solutions. The Stability of Non-Cyclic Benzyl Aryl Ethers During Lignin Biosynthesis. In Holzforschung - International Journal of the Biology, Chemistry, Physics and Technology of Wood, pp. 275.

Sjöström, E. (1993) Wood Chemistry Fundamentals and Applications 2nd edn.: San Diego, CA: Academic Press.

Taboada-Puig, R., Lú-Chau, T., Eibes, G., Moreira, M.T., Feijoo, G. and Lema, J.M. (2011a) Biocatalytic generation of $\mathrm{Mn}$ (III)-chelate as a chemical oxidant of different environmental contaminants. Biotechnol Progr, 27, 10.1002/btpr.1585.

Taboada-Puig, R., Lú-Chau, T., Moreira, M.T., Feijoo, G., Martínez, M.J. and Lema, J.M. (2011b) A new strain of Bjerkandera sp. production, purification and characterization of versatile peroxidase. World J Microbiol Biotechnol, 27, 115122.

Taboada-Puig, R., Lu-Chau, T.A., Eibes, G., Feijoo, G., Moreira, M.T. and Lema, J.M. (2015) Continuous removal of endocrine disruptors by versatile peroxidase using a two-stage system. Biotechnology Progress, 31, 908-916.

Tolbert, A., Akinosho, H., Khunsupat, R., Naskar, A.K. and Ragauskas, A.J. (2014) Characterization and analysis of the molecular weight of lignin for biorefining studies. Biofuels, Bioproducts and Biorefining, 8, 836-856. 
Yoshida, S., Tanahashi, M., Shigematsu, M. and Shinoda, Y. (1994) Effect of reaction medium on dehydrogenative polymerization of sinapyl alcohol. Mokuzai Gakkaishi, 40, 974-979.

Mu, W., Ben, H., Ragauskas, A. and Deng, Y. (2013) Lignin Pyrolysis Components and Upgrading-Technology Review. BioEnergy Research, 6, 1183-1204.

R_Developmnet_Core_Team (2011) $R$ : a language and environment for statistical computing: Vienna, Austria : the R Foundation for Statistical Computing.

\section{TABLES}

Table 1. Effect of the $\mathrm{H}_{2} \mathrm{O}_{2} / \mathrm{CA}$ ratio and $\mathrm{pH}$ on molar mass and polydispersity.

\begin{tabular}{ccccc}
\hline pH & $\mathrm{H}_{2} \mathrm{O}_{2} / \mathrm{CA}$ ratio & $\mathrm{Mn}(\mathrm{g} / \mathrm{mol})$ & $\mathrm{Mw}(\mathrm{g} / \mathrm{mol})$ & $\mathrm{Pd}$ \\
\hline 4.5 & 0.5 & 1300 & 4500 & 3.5 \\
4.5 & 0.75 & 2000 & 48800 & 24.5 \\
4.5 & 1.0 & 2300 & 80100 & 35.4 \\
4.5 & 1.5 & 2800 & 83600 & 29.9 \\
4.5 & 2.0 & 2100 & 41600 & 20.2 \\
3.0 & 1.0 & 1300 & 4600 & 3.6 \\
6.0 & 1.0 & 850 & 1500 & 1.8 \\
7.5 & 1.0 & 800 & 1300 & 1.7 \\
\hline
\end{tabular}




\section{FIGURE LEGENDS}

Figure 1. Chemical structures of three monolignols: (A) p-coumaryl alcohol, (B) coniferyl alcohol and (C) sinapyl alcohol and the mechanism of the polymerization of CA by the oxidative action of $\mathrm{Mn}^{3+}$

Figure 2. Effect of $\mathrm{pH}$ on DHP structure: $(\mathrm{A})$ guaiacylglycerol- $\beta$-guaiacyl ether, $(B)$ benzyl aryl ether and $(\mathrm{C})$ retro-aldol product.

Figure 3. Effect of (a) $\mathrm{H}_{2} \mathrm{O}_{2} / \mathrm{CA}$ ratio and (b) treatment $\mathrm{pH}$ on precipitation yield and deactivation of the enzyme. Precipitation yield (grey columns) and residual activity (white columns).

Figure 4. Schematic diagram of the two-stage system for the $\mathrm{Mn}^{3+}$-malonate production. [1] Enzymatic reactor; [2] polymerization reactor; [3] ultrafiltration membrane.

Figure 5. The effect of (a) $\mathrm{H}_{2} \mathrm{O}_{2} / \mathrm{CA}$ ratio, (b) treatment $\mathrm{pH}$ and (c) oxidizing system, on pyrolysis yields.

Figure 6. The effect of (a) $\mathrm{H}_{2} \mathrm{O}_{2} / \mathrm{CA}$ ratio, (b) treatment $\mathrm{pH}$ and (c) oxidizing system, on the distribution of pyrolysis degradation products.

Figure 7. PCA of the pyrolysis data for DHPs. (a) Score plot of two principle components dividing the samples into two groups and (b) loading plot indicating that guaiacyl and $p$ hydroxyphenyl pyrolysis products are important for the classification of samples seen in the Score plot. 